\title{
DIPLOMATIC SKILLS USED FOR INTERNATIONAL MARKETING PRACTICE
}

\author{
Bahles, $M$.
}

In international management, there are observable difficulties in development processes and international alignments similar to situations in international diplomacy. This article presents application of the theories and concepts of international diplomacy on the practice of international marketing. It is the first application of the concept of international diplomacy for management, especially marketing practices. The goal of the article is to elaborate the concepts and solutions of international diplomacy for international marketing. The used research method is secondary analysis of existing theories and concepts of diplomacy in combination with expert interviews with international diplomats as well as international marketing practitioners. The results of the presented examination have interesting managerial implications for international marketing development processes, showing that the virtues of international diplomacy can be adapted to the practice of international marketing.

JEL classification: M31

Keywords: International marketing; international management; international negotiation; diplomacy.

\section{Introduction}

"That does not work in our market", this is the standard expression when international marketing concepts, in particular communication concepts, are presented to international stakeholders for use in several international markets. Usually, there is some resistance to using and adapting international concepts by other markets. There are cases where this happens less and international concepts are more likely to be used; however, some resistance can be observed for sure. This observation led the author to consider how these barriers and obstacles in international work can be reduced or resolved. Due to the fact that international collaboration is about dealing with people from different international backgrounds and therefore about anticipating their personal contexts, situations and needs as well as cultural differences in order to achieve a common goal, strong similarities are observed in the procedures of international diplomacy and negotiations. "It is only negotiation that can produce the advantages obtainable from the cooperative pursuit of common interests" (Berridge, Keens-Soper and Otte, 2001).

The concepts used in the area of diplomacy should be examined and considered for supporting the development of international marketing concepts. The objective of this paper is to identify general procedures and outline some "golden rules" on how to act in international collaboration in order to succeed in finding a common solution or reaching "consensus" as it is called in international diplomacy.

\section{Methodology}

In order to identify general procedures and concepts of international diplomacy and to adapt them for international marketing practice, the basic literature about diplomacy should be examined as well as recent and more practical publications in this field.

In addition, the main source of information about diplomatic procedures and tactics was identified via personal interviews (expert interviews) conducted with international diplomats from Czech Republic and Germany (number of interviews: 4) as well as with international marketing practitioners from Czech Republic and Germany (number of interviews: 4 ) in order to identify the similarities of both perspectives, and especially to identify and learn from the specific procedures and tactics from international diplomacy which are applicable to the practice of international marketing.

\section{Questions asked in the interviews:}

1. What are the success-factors in international diplomacy/ marketing?

2. How do you proceed in international diplomacy/ marketing? 
3. What role do cultural differences play in international diplomacy/ marketing?

4. What are the "golden rules" of international diplomacy/ marketing?

\section{Findings}

Before examining international diplomatic concepts and theories in order to adapt them for the international marketing practice, the actual side of international marketing development should be described to show the parallels to international diplomacy and especially the need to find alternative concepts and new ways to optimize the international collaboration in this field.

\section{The Marketing Practice Side}

The development of international marketing concepts, in particular international communication concepts, is always a complex challenge. Many participants and international stakeholders are involved in the development process in order to achieve the best solution in all the related markets and meet the expectations of everybody involved.

In order to do so, multinational companies follow either a more centralized approach with low involvement of the countries or a more decentralized approach with higher openness and involvement of the main target markets for which the communication is planned.

The first approach leads to high efficiency (time and cost savings) of the development process but often to high frustration on the side of the local managers who cannot bring in their market knowledge and personal managerial competence. The second approach reacts to this circumstance and offers higher involvement of the local experts, but this procedure is more complex and difficult to manage and coordinate.

"Sometimes I feel like a diplomat." says an international marketer responsible for the international development of marketing and communication concepts. The task is very much about coordinating the international colleagues; involve them in the development process, and also to come up with an effective international concept in the most efficient way. There is the tension between achieving the most relevant solution for all the different countries and developing such a concept in the most efficient way. In today's business world the managers have to meet the requirements for speed and efficiency of the process. Here, a more decentralized approach has the disadvantage that the development is not fast enough and could get stuck in excessive international alignment. The challenge and task for international marketing managers is therefore to balance international collaboration in the most effective and optimal way.

The experience of the author is that diplomatic manners and ways of communication can support and enhance in the international collaboration and therefore make the development process even faster and more efficient. The perception of the international marketers is that it is even more difficult in international marketing and communication development than in international political relations because it is less based on actual facts and legal framework and is ultimately subjective. Therefore, multiple international opinions are more difficult to handle and it is more difficult to agree. "I think collaboration in the EU is even easier. It is about facts and laws. Advertising is always to some extent subjective."

Definitely, there are similar experiences and general recommendations where international collaboration is successful: "It is important to involve the international governors very early." "It is all about to achieve buy in." Also, on the side of the local stakeholders, the necessity of an open, two-way collaboration is seen: "The local marketers have to buy in the campaign by heart. They have to invest their budget into it." Involvement should not be done only for "political" reasons; it is also necessary to achieve the best factual solution. "It makes a lot of sense to profit from the knowledge and also creativity of the local marketers." To coordinate and to handle the common process is not easy. To get everybody on board and to align all the different opinions takes time and effort. It is like the old expression "too many cooks spoil the broth". "The more people that are involved, the less honest is the feedback." For this reason, it is more about meeting and communicating on a regular basis while meeting the requirements of efficiency. "You have to create a personal bond. Many decisions and discussions are later with a beer." "Finally, it is about creating trust. Good results help here."

In order to achieve proper results and to coordinate the common development, a defined process can be of great help. This process should be clear to everybody but should also be flexible to react to situational changes and unexpected developments. "A clear process helps. It is also developing - a learning system." To create some neutrality and security in the development process, research can play a special role. It creates objectivity in an area dominated by subjectivity such as creative communication. "Neutral research is important for alignment."

Within the process the roles, responsibilities and also the decision power have to be clear. Apparently, 
it is important not only to involve the international stakeholders but also to define boundaries and a clear decision-making process: "The lead and the decision making should happen at the headquarters. Brand leadership is not democratic." "We exchange today only with the marketing director level, because they decide. On the deputy level, it does not make sense." In an ideal process, the steps of development are clear for everybody; everybody has the feeling of being involved and heard, and that there is enough space for discussion and common alignment. The result is a common solution and concept that is indeed relevant in the markets (proven by neutral market research) and approved by all the international stakeholders. It is an ideal result that is definitely not easy to achieve. It is a huge effort not only based on a professional procedure and clear development steps, but also based on the success of interpersonal collaboration. "For the last development process, I deserve a medal of honor." "It needs small concessions. You have to see what you can do for the countries 'requirements."

For this interpersonal collaboration, one also has to take into account the different mentalities of the international colleagues. From personal observation, German managers tend to act and communicate in a very straightforward and direct manner. They want to achieve a common solution as fast and efficiently as possible and do not necessarily appreciate counter or alternative thoughts. The British colleagues tend to be more open and diverse and appreciate an eloquent discussion. Due to the "British politeness" they are occasionally irritated by the direct communication and argumentation of the German participants. This appreciation for an intellectual debate is even stronger with the colleagues from France. They usually do not take the first approach and the further development steps for granted. They like to question the current development and seem to enjoy intellectual discussion about the topic. The colleagues from Italy seem to be more relaxed about the discussion. With friendliness and charm, they often create a more light-hearted atmosphere and moderate between the different opinions. A bit similar is the way of communication of colleagues from Spain who are also more emotional in their behavior but a bit more fixed with their point of view.

A further examination based on the experiences of international diplomacy and from the literature about intercultural communication should be conducted in the next chapter in order to deal with the complex intercultural collaboration best.

\section{Lessons from the World of Diplomacy}

After identifying the challenges in the practice of international marketing, the experiences, concepts and tactics of international diplomacy should be examined in order to find ways that can be adapted to optimize the international collaboration in the development of international marketing, i.e. communication concepts.

K. Hamilton and R. Langhorne describe in "The Practice of Diplomacy" (2011), the virtue of professional diplomacy: ...the professional diplomat's experience of a wide variety of postings, his mastery of foreign languages or his intuitive grasp of circumstances - his Fingerspitzengefühl.

Also "Satow's Diplomatic Practice" (Roberts, 2009) defines diplomacy as "the application of intelligence and tact to the conduct of official relations between the governments of independent states, extending sometimes also to their relations with dependent territories, and between governments and international institutions; or more briefly, the conduct of business between states by peaceful means." That is to say, that diplomacy is not only about using intelligence but also tactful manners for international negotiations.

In this fundamental book, there is also some general advice for diplomats referring to Callières in his famous work "De la manière de negocier avec les souverains": A good negotiator should have enough self-control not to speak without having asked himself what he has to say. A man who displays self-possession and calmness under pressure has a great advantage in negotiation over a man who is lively and fiery. To succeed in this profession, you need to speak much less than to listen. A wise and capable negotiator needs to adjust himself to the habits and customs of the country where he lives without showing repugnance or contempt for them. He should know or learn the history of the country where he is resident and so recount the great deeds of the ancestors of the country's leaders or indeed their own deeds which will incline them to look kindly on the negotiator. It's more of an advantage for a negotiator to carry out his business orally. This way he has more opportunity to discover the feelings and aims of his interlocutors and to put over his own arguments more forcefully. One of the greatest secrets of negotiating is knowing how to distil drop by drop into the mind of interlocutors the matter of which one wants to persuade them.

In other words, a diplomat is successful when he or she is very empathetic to the context and the needs of the other side. They should prepare very much in advance also in order to understand local circumstances and even historical backgrounds. Personal communication 
is always better to get a holistic understanding of the communication and to avoid misinterpretations.

Very similar, the more recent book of communication scientist Frank Naumann defines 20 laws for diplomatic communication (Naumann, 2012). Actually, all of them are adaptable to the marketing practice when you work in a group with international stakeholders and colleagues:

- Law 1: Show resiliently in style, but be hard on the matter.

- Law 2: Prove more patience than your counterpart

- Law 3: Instigate peace before the conflict escalates.

- Law 4: Help all parties to save face.

- Law 5: Collect and maintain information and contacts.

- Law 6: Lead the conversation.

- Law 7: Be honest, but you give only the information that is expected of you.

- Law 8: Communicate suggestions instead of demands.

- Law 9: Search even in the sharpest contrast for connecting similarities.

- Law 10: Declare yourself an ally.

- Law 11: If you get into a clinch, announce a temporary withdrawal.

- Law 12: Offer alternatives, but give them before others come up with theirs.

- Law 13: Motivate your partner by the prospect of fabulous profits.

- Law 14: Don't break up Gordian knots, but you put on salami tactics.

- Law 15: Overcome mental barriers by a trial play through of alternative scenarios.

- Law 16: Strive for creative agreement, not for a half compromise.

- Law 17: Give your partner the authorship of your agreement.

- Law 18: Congratulate your counterpart to a victory, even if you have the edge.

- Law 19: Practice yourself in the art of small gestures.

- Law 20: Maintain your reputation as a strong, understanding partner.

These laws are mainly about not following a straight and linear way; instead, find a smarter and more creative side way if you want to achieve your professional goal. Be a lot more empathetic to the other side and try to understand their perspectives and goals. Think ahead like a strategic diplomat and don't let yourself be led by others. But don't force the leadership; instead create it via reasonable and calm argumentation, trust and building a bridge between your intensions and the intensions of the international counterparts. Be more sensitive and open-minded about others in many conflictive international meetings and discussions.

This is also, what international diplomats stated in the conducted interviews: In diplomacy, it is important to always be professional and polite but with a strong will and clear intension. "Diplomats are always very friendly and polite." "Be polite but strong." One has to be flexible and adjust to the new developments. "Diplomacy is the ability to adapt to different situations." But one has to prepare well in advance. The more one knows about the topic and the counterpart, the better. "Know the issue. Be prepared." "You have to know the different parties involved." Not only are official reunions important. Sometimes even more important are the discussions and alignments before or afterwards. "Parallel to the official meetings, there are informal alliances and informal groupings." It is important that the common results are defined and fixed. "The protocol is very important. Everything is documented and written down." On the other hand, a common solution and further proceeding can even take longer in international diplomacy. "Nothing is agreed, until everything is agreed." Also in international diplomacy, it is often the case that not everybody can be satisfied at the end. "A general rule: Nobody is satisfied but everybody can live with it. It is all about achieving a consensus."

Nevertheless, it is important to work positively and constructive together. "It is also important to create friendships with international colleagues." "Create a connection and relationships." Like "Harold Nicolson proclaimed as the art of diplomacy: Its purpose is to create international trust" (Sallet, 1953).

In discussions and debates, be very much aware how one acts and communicates. Choose your words and arguments wisely. "Think twice before you say something. It is important to understand what is the vision behind the other's acting." For this, you have to be a great communicator. "Have superior rhetoric skills." This is an advantage for the colleagues from the UK and the US because they are native in English. It is a natural advantage in the debate. Also, in this context, know about the different communication styles of the international colleagues. "Know about cultural differences and the local mentality of the people." Overall, be flexible and creative in the solution finding but within the framework 
and the defined procedure. "Be open minded and flexible but know the red lines of your country.

At the end it needs a final decision about the main direction and final concept. After all the exchange and the debate there has to be made the decision - often on a higher level or with the support of neutral market research. "But at the end it is also about leadership." "At the end the ministers decide." Market research is a tool that does not exist in international diplomacy. On the other hand, there is the procedure of voting what is not that common in the international marketing practice but could be maybe in the future a possible tool in the international alignment. Helpful for this are new digital communication possibilities, like email exchange or internal online surveys (Bilgeri and Wolf, 2004).

\section{Particular Recommendations for International Negotiations}

In order to give some country specific advice, the author would like to present some particular recommendations when negotiating with certain international regions and cultures. Following the book of Frank L. Acuff "How to negotiate with anyone anywhere around the world" (Acuff, 2008) cultural differences should be taken into consideration in international negotiation:

\section{Western Europe}

In Western Europe, there is a quite direct style to negotiate though there are certain differences between the single countries, especially from the North to the South of Europe. Communication and negotiations are rather straightforward, issue oriented and start overall punctually. The countries in Western Europe are more individual oriented and therefore everybody makes his personal point in a discussion. The challenge in international collaboration in Western Europe is therefore to bring all different opinions and points of view together.

\section{Eastern Europe}

The communication style in Eastern Europe is quite direct; it is made clear if somebody disagrees. On the other hand, nobody is criticized in front of a group. The decision-making is also group oriented and the decision process is quite formal and bureaucratic. Mostly everything has to be checked and finally decided by the higher authority, i.e. management level.

\section{Asia}

Similar to Eastern Europe but even more so, the decisionmaking in Asia overall is very group oriented. Meetings regularly have a lot of participants and everybody is involved in the decision. Building trust is very important; therefore, personal relations play a great role and the decision process takes longer. The communication is very polite; therefore it is difficult to identify the actual opinion and to plan the following steps within the process.

\section{North America}

Communication and decision-making in North America is a lot more direct and straight to the point. The communication and the proceeding in the process shall be effective and efficient. North America's communication is friendly and polite but pretty clear and oriented towards the issue. Therefore, straight communication with reasonable arguments is most promising.

\section{Latin America}

In Latin America, the individuality of the person is very much valued. Therefore, personal aspects are very important when working together. First you have to get to know each other, then the topics are discussed. The decision is made by the organization but people in Latin America are proud to communicate their personal points of view in a discussion. Meetings and discussions are less formal and strict than in other regions (e.g. Western Europe and Asia).

\section{Arabic countries}

The Arabic way of communication is very polite, that is to say it can even "flourish" and be emotional, though this emotionality can lead in a disagreement to some extreme and loud reactions. This can happen for instance in bargaining (which is a big tradition in the Arabic countries) and it may also occur in international collaboration discussions on other issues, e.g. related to marketing concepts.

These short portraits of communication and discussion styles are only a general overview about the cultural differences when working together. In case of a particular project with colleagues from certain countries, it would be necessary to check for the single country profiles and descriptions in the book of Frank Acuff.

\section{Conclusion}

As the examination shows, there are certain differences in international communication and collaboration. Intercultural differences in communication should be taken into consideration when working together. To handle the complex situation of international collaboration in international marketing practice, the 
experiences and concepts of diplomacy can be helpful. The following is a summary of the main implications of international diplomacy, the so to say "golden rules" of international collaboration in diplomacy and marketing practice. These principles can work as general guidelines when working on international projects with colleagues from various countries.

\section{The "12 golden diplomatic and international} marketing rules":

1. Involve the international stakeholders at an early stage, make them part of the development.

2. Have a clear and formal process that everybody knows about.

3. Conduct research as a tool of factual decision-making.

4. Create trust and a personal bond with international colleagues; also, always be friendly and polite but strong of will.

5. Be aware of "informal grouping" and take it into consideration.

6. Be transparent about the outcomes; have the results in a written form.

7. Have strong leadership but personal empathy to the context and the interests of the international representatives.

8. Anticipate what is important to local stakeholders understand what is behind their argumentation.

9. Have patience and listen before you speak.

10. Be flexible and open but clear about your goal.

11. Be prepared for the possible outcomes and discussions (think ahead about different scenarios).

12. Create a win/win-situation as a "consensus".

\section{References}

Acuff, F. L. (2008). How to negotiate with anyone anywhere around the world. Third Edition. New York: Amacom/ American Management Association.

Berridge, G. R. (2002). Diplomacy. Theory and Practice. Second Edition. New York: Palgrave.

Berridge, G. R., Keens-Soper, M., Otte, T. G. (2001). Diplomatic Theory from Machiavelli to Kissinger. New York: Palgrave.

Bilgeri, A., Wolf, A. (2004). Diplomatie digital. Neue Kommunikationswege in der internationalen Politik. Barbara Budrich, Opladen, 53.

Hamilton, K.; Langhorne, R. (2011). The Practice of Diplomacy. Its Evolution, Theory and Practice. Second Edition. Routledge, 258.

Naumann, F. (2012). Die Kunst der Diplomatie, 5th ed. Rowohlt, 17-248.

Roberts, I. (2009). Satow's Diplomatic Practice, Sixth Edition, Oxford University Press.

Sallet, R. (1953). Der Diplomatisceh Dienst. Deutsche Verlagsanstalt. Stuttgart, 17.

Author

Diplom-Kaufmann Michael Bahles Assistant Professor Department of International Trade Faculty of International Relations University of Economics, Prague Nám. W. Churchilla 4, 13067 Prague 3, Czech Republic michael.bahles@vse.cz 